\title{
A Comparison between the Same-Ethnicity and Cross-Ethnicity Friendship Quality of Adolescents in Viet Nam
}

\author{
Le To Do Quyen ${ }^{1} \&$ Norzarina Mohd-Zaharim ${ }^{1}$ \\ ${ }^{1}$ School of Social Sciences, Universiti Sains Malaysia, Penang, Malaysia \\ Correspondence: Le To Do Quyen, School of Social Sciences, Universiti Sains Malaysia, 11800USM Pulau \\ Pinang, Penang, Malaysia. Tel: 60-612-460-2399. E-mail: gamen20032003@gmail.com
}

Received: September 26, 2014

Accepted: October 30, $2014 \quad$ Online Published: February 17, 2015

doi:10.5539/ijps.v7n1p1

URL: http://dx.doi.org/10.5539/ijps.v7n1p1

\begin{abstract}
The present study aims to explore the differences between the same-ethnicity and the cross-ethnicity friendship quality of adolescents in Viet Nam. Participants were 200 ethnic majority students and 200 ethnic minority students from two public high schools in DakLak, Viet Nam. The participants answered the McGill Friendship Questionnaire-Respondent's Affection (MFQ-RA). The findings showed that there was no significant difference in the same-ethnicity friendship quality between adolescents from ethnic majority and minority groups. However, in terms of the cross-ethnicity friendship quality, adolescents from the ethnic minority groups got significantly higher positive feelings for friends than those from the ethnic majority group. The results revealed that the differences between genders in the same-ethnicity friendship quality were significant. Meanwhile, there were significant differences between genders in cross-ethnicity friendship quality. In fact, girls got significantly higher positive feelings for a friend and the overall same-ethnicity friendship quality than boys. These findings are discussed vis-à-vis previous research on intra- and inter-ethnic friendships and gender comparisons in friendships.
\end{abstract}

Keywords: friendship quality, adolescents, ethnicity, gender, Viet Nam

\section{Introduction}

\subsection{The Role of Friendship Quality in Individuals' Life}

Friendship is a distinctively personal relationship characterized as intimacy and formed by the concerns of a person for the welfare and the sake of the other. Friendship plays a key role in our lives as a part of a broader set of concerns. It also refers to a special concern for friends since our friends can help shape our characteristic (Helm, 2005). Friendship has therefore a good influence on the developmental, environmental, and social aspects of individuals across all cultures throughout their lifespan. Numerous studies have explored how friendship affects psychological well-being (Moore \& Boldero, 1991; Parker \& Asher, 1993; Thomas \& Daubman, 2001; Waldrip, Malcolm, \& Jensen-Campbell, 2008).

Friendship quality can be considered as people's "impression of the degree to which a given relationship meets specified needs ranging from the provision of opportunities for play and companionship to allowing intimate disclosure and exchange" (Nangle, Erdley, Newman, Mason, \& Capenter, 2003). Friendship quality is particularly important because it not only has direct effects on many aspects of children's social development, including their self-esteem and social adjustment, but also has indirect effects on their attitudes and behaviors (Berndt, 2002). A number of theorists have claimed that friendship quality has both positive and negative aspects. According to these researchers, positive aspects involve companionship, trust and support, disclosure, communication and validation, prosocial behavior, self-esteem support, intimacy, loyalty, etc. Meanwhile, negative aspects refer to conflict and betrayal, dominance attempt, and rivalry of the relationship (Berndt, 2002; Parker \& Asher, 1993). In fact, Berndt and Keefe (1995) stated that adolescents' self-esteem and psychological health may be enhanced by high-quality friendships.

Berndt (2002) also suggested that variations in friendship quality affect the magnitude of friends' influence on each other by measuring friends' characteristics and friendship. He also confirmed that the high-quality friendships enhance many aspects of children's social development in terms of their self-esteem and social adjustment, regardless of the characteristics of those friends. Friendship quality depending on friends' 
characteristics has both direct effects and indirect effects on children. "A high-quality friendship is characterized as high levels of prosocial behavior, intimacy, and other positive features, and low levels of conflicts, rivalry, and other negative features" (p. 7). As a general rule, the moral socialization from early caretakers to parents or family builds individuals' first values (Friedman, 1989). On the other hand, their friends' needs, fears, experiences, projects, and dreams make them explore the significance and worth of values and standards. Consequently, it can form their new standpoints. It can be explained by the following hypotheses.

Friedman (1989) suggested that appealing to the notion of bestowal is another way to interpret this issue. According to her, two factors, namely the sharing viewpoint and the commitment among friends should be focused. Firstly, by evaluating what our friends' values, eliminating or coming to adopt friend's values as parts of our own sense of value, friendship enables us to be aware of experiences and sights of our acquaintances from their own opinions as well as gaining knowledge and values which differ from our own. Secondly, loyalty helps keep a unique person as a friend for a long time. That lets us discover her or his values, interests, reasons, etc. in order for us to value and think similarly. Friends strongly affect the sense of values and promote their friendships and intimacies as a result of sharing. Crandall, Schiffhauer and Harvey (1997) also hypothesized that individuals form friendships through dimensions they value. The "fault lines" around them are represented by these dimensions of value, which help classify themselves into the larger social group of which they are members.

It was assumed that there is a difference in friendships between girls and boys. For example, girls have more self-disclosure, empathy, interdependence, and need for nurturance in an intimate friendship, whereas boys normally search for companionship, competition, control, and conflict in larger friendship groups. Differences in how relationships are perceived or evaluated could result in differences in friendship quality, and males and females have different views of friendship (Bae, 2003; De Goede, Branje \& Meeus, 2009; Rodebaugh, Fernandez \& Levinson, 2012). Previous studies have indicated that there is a slightly significant difference in underlying construct of friendship quality between males and females. In several important ways, the friendships of males and females are assumed to be different. It was demonstrated that the markedly gender differences in childhood peer relationships may extend into adulthood (De Goede et al., 2009).

\subsection{The Same-Ethnicity Friendship and Cross-Ethnicity Friendship}

Data obtained from a study of Williams (1959) demonstrated that when people "reach out" into the larger community, they tend to select friends from persons having a larger number of value orientations similar to them. Larson (2010) also suggested that perceived similarity in terminal and instrumental values play an important role in maintaining low conflict and high depth within friendships. Moreover, previous studies have highlighted the influences of environmental or contextual characteristics on the interethnic formation of friendship. The more opportunity for intergroup contact, the higher the quality of friendship achieved. Likewise, the lower the intergroup contacts, the lower the quality of friendship achieved (Blau, 1977). On the other hand, culture influences individuals' developmental and social processes, and it can be considered as an important shaper of mind. Therefore, the various societies' cultural norms and values may lead to differing friendship qualities across cultures (Bae, 2003). Various cultural differences in friendship characteristics, namely the meaning of friendship, the norms and values exist and guide friendship behavior or the styles of friendship. In other words, cultural values have strongly impacted on friendship characteristics and ethnicity as an index of cultural distinctions may influence how friendship quality is perceived (Rodebaugh et al., 2012). Ethnicity is therefore a major factor that should be taken into account when we explore friendship quality. In case of members from a minor group within a particular setting, they tend to make friends with others in their own social categories whose personal interests are similar to themselves than others from different social categories. Similarly, among people from the major group within a particular setting, they are more likely to form friendships based on similarities in personal dimensions (Crandall, Schiffhauer, \& Harvey, 1997). In that case, the strengthened salience of social identity may result in the limit of available friendship choices for minor members. In fact, the limitation of options causes the limitation of the assortment through a number of similar dimensions (interest, physical, value...)

The influence of race on friendship is far greater than similarity in parental socioeconomic status or mother's educations (Quillian \& Campbell, 2003). Very few interracial friendships are mentioned since an adolescent's probabilities of forming the same ethnicity friendship are about 1.8 times those of forming an interethnic friendship (Moody, 2001). The same-ethnicity friendships are more stable than interethnic friendships, even after controlling for a variety of contextual and dyadic characteristics such as school ethnic composition and friends' similarities in attitudes and behaviors. Reciprocity and closeness are strong predictors of friendship stability and appear to dampen the effects of ethnicity. This suggests that ethnicity plays an important role in structuring the social lives of adolescents. The quality of interethnic friendships, as measured by degree of reciprocity and closeness should be taken into consideration (Rude \& Herda, 2010). Interracial friendships symbolize the equal 
status contact that is necessary for reducing racial prejudice (Rude \& Herda, 2010; Slavin \& Cooper, 1999). Interracial friendships are believed to improve racial attitudes as well as provide individuals from minority ethnic groups with more chance to access the resources and opportunities of the dominant group. Cross-race friendships can also be considered as "bridging ties" among different social networks (Briggs, 2007).

These days, young people from ethnic minority groups in Viet Nam have more chances to study, live or work with those from the major groups. It has become a major issue, especially for the ethnic minority groups. They expect to have more friends from the major groups; however, they hardly want to suffer from racial discrimination. Once they belong to the dominant group, they hope that the "membership can confer large boosts in status, and it helps people to achieve main goals, and it can assist them in refining and clarifying their own self-concepts, and encourage them to make a contribution to obtaining desired changes in society" (Baron, Byrne, $\&$ Branscombe, 2006). Due to undoubtedly important benefits, they attempt to make more friends from the major group even though these relationships cannot bring them trust, empathy, and intimacy as the friendships with those from their own groups (Telfer, 1971). Otherwise, they are continuously satisfying with friends from the same ethnic minority groups and loose a chance to get conveniences from interethnic friendships. Hence, knowing how to get positive participation in cross-culture society including complex ethnic groups is a major concern for them. However, very few studies were conducted to find out the quality of the same-ethnicity and cross-ethnicity friendship quality of adolescents in Viet Nam in order to gain deep insights into their problems in multiracial friendships.

\section{Methodology}

\subsection{Participants and Procedure}

Vietnam has 54 ethnic groups: the largest group named Kinh or Viet, accounting for 86 percent of the population; the next largest groups are Tay, Thai, Muong, Khmer, Hoa, and Hmong which together make up 10 percent of population; and the remaining ethnic groups represent 4 percent of population. Although the terms "indigenous people" are refered to ethnic groups of smaller size than the majority group in Viet Nam, the preferred terminology is ethnic minority groups (Nam, 2004). In the present study, non-probability convenient sampling was used to select participants. They were 200 ethnic majority students (Kinh) and 200 ethnic minority students (Ede, Mnong, Tay, Nung, Dao) from two public high schools in DakLak, Viet Nam (mean age $=15.26, \mathrm{SD}=.57$; $71 \%$ female). The participants answered a questionnaire in class under the guidance of the researcher (i.e., the first author). Conducting the research at two high schools was later accepted and supported by the Ministry of Education and the school principals.

\subsection{Measurement}

Friendship quality was measured by using McGill Friendship Questionnaire-Respondent's Affection (MFQ-RA) (Mendelson \& Aboud, 1999, 2012). This 16-item questionnaire has two subscales designed to assess two components of friendship quality: positive feelings for a friend (9 items) (e.g., "like x a lot") and friendship satisfaction (7 items) (e.g., "pleased with my friendship with x"). Respondents were asked to indicate the degree of agreement with each positively worded item on a 9-point Likert scale ranging from - 4 to 4 and to think about their closest friendships while answering the items. Each participant completed one MFQ-RA for the same-ethnicity best friend and one for the cross-ethnicity best friend. The average of all the items determined the positive feelings for a friend and friendship satisfaction of the participants, with the higher scores reflecting the higher friendship quality.

This instrument was translated from English into Vietnamese and was adapted for Vietnamese students. Forward translation method was used for questionnaire translation before sending it to Viet Namese psychologists as well as to English experts for revision and correction. To determine the reliability of the MFQ-RA (Viet Namese version), Cronbach's alpha $(\alpha=0.85)$ was employed. A factor analysis with oblique rotation applied to the MFQ-RA yielded a two-factor solution (eigenvalues $=9.2,1.0 ; \%$ of variance $=57.6,6.2$ ). Factor 1 consists of six satisfaction items, which were averaged as one subscale. Meanwhile, factor 2 has the ten other positive-feelings items, which were averaged as another subscale.

\section{Results}

\subsection{A Comparison of the Same-Ethnicity and Cross-Ethnicity Friendship Quality between Ethnic Majority and Minority Adolescents}

To examine ethnicity and gender differences in participants' friendship quality dimensions, $t$-tests were used. In this work, ethnicity and gender are independent variables. Two domains of friendship quality are dependent variables. Table 1 presents the means and standard deviations for the friendship domains as well as overall 
same-ethnicity friendship quality for adolescents from ethnic majority and minority groups. Although the results indicated that the means of "friendship satisfaction", "positive feelings for a friend" and overall friendship quality for ethnic minority adolescents were slightly higher than those for ethnic majority adolescents, these differences were not statistically significant.

Table 1. A comparison of the same-ethnicity friendship quality between ethnic majority and minority adolescents

\begin{tabular}{lllll}
\hline Friendship Quality Dimension & Ethnicity & $M$ & $S D$ & $t(p)$ \\
\hline Friendship satisfaction & Majority & 1.51 & 1.30 & $-.074(.941)$ \\
\multirow{2}{*}{ Positive feelings for a friend } & Minority & 1.52 & 1.00 & \\
& Majority & 2.21 & 1.29 & $-.710(.478)$ \\
Overall & Minority & 2.29 & .888 & \\
& Majority & 1.95 & 1.23 & $-.494(.622)$
\end{tabular}

Note. ${ }^{* \mathrm{p}<.05 ; * * \mathrm{p}<.005 ; * * * \mathrm{p}<.001}$

The means of the two friendship dimensions and overall cross-ethnicity friendship quality for ethnic minority adolescents were higher than those for ethnic majority adolescents. As can be seen in Table 2, significant differences were found in "positive feelings for a friend" $(t(335)=-2.080, p<.05)$. Meanwhile, there was no significant difference in "friendship satisfaction" and overall friendship quality.

Table 2. Comparison of cross-ethnicity friendship quality between ethnic majority and minority adolescents

\begin{tabular}{lllll}
\hline Friendship Quality Dimension & Ethnicity & $M$ & $S D$ & $T(p)$ \\
\hline Friendship satisfaction & Majority & 1.35 & 1.60 & $-1.386(.167)$ \\
\multirow{2}{*}{ Positive feelings for a friend } & Minority & 1.54 & 1.12 & \\
& Majority & 1.93 & 1.62 & $-2.080\left(.038^{*}\right)$ \\
Overall & Minority & 2.22 & 1.02 & \\
& Majority & 1.71 & 1.56 & $-1.893(.059)$
\end{tabular}

Note. ${ }^{* \mathrm{p}}<.05 ; * * \mathrm{p}<.005 ; * * * \mathrm{p}<.001$

\subsection{A Comparison of the Same-Ethnicity and Cross-Ethnicity Friendship Quality by Gender}

The means of same-ethnicity friendship quality for male adolescents were lower than those for female adolescents, for the two friendship dimensions and overall cross-ethnicity friendship quality (see Table 3 ). $t$-tests revealed that there were significant differences in "positive feelings for a friend" $(t(184)=-2.076, p<.05)$ and in the overall same-ethnicity friendship quality $(t(186)=-2.040, p<.05)$. However, there was no significant difference in "friendship satisfaction" between genders. 
Table 3. Comparison of same-ethnicity friendship quality by gender

\begin{tabular}{lllll}
\hline Friendship Quality Dimension & Gender & $M$ & $S D$ & $t(p)$ \\
\hline Friendship satisfaction & Male & 1.39 & 1.28 & $-1.336(.183)$ \\
\multirow{2}{*}{ Positive feelings for a friend } & Female & 1.57 & 1.10 & \\
& Male & 2.05 & 1.24 & $-2.076\left(.039^{*}\right)$ \\
Overall & Female & 2.33 & 1.04 & \\
& Male & 1.80 & 1.18 & $-2.040\left(.042^{*}\right)$ \\
\hline
\end{tabular}

Note. ${ }^{* \mathrm{p}}<.05 ;{ }^{* * \mathrm{p}<.005 ; * * * \mathrm{p}<.001}$

Table 4 shows that female adolescents had higher cross-ethnicity friendship quality than male adolescents for the two friendship dimensions and overall cross-ethnicity friendship quality. However, $t$-tests showed that there was no significant differences in "friendship satisfaction", "positive feelings for a friend" and overall cross-ethnicity friendship quality between genders.

Table 4. Comparison of cross-ethnicity friendship quality by gender

\begin{tabular}{lllll}
\hline Friendship Quality Dimension & Gender & $M$ & $S D$ & $t(p)$ \\
\hline Friendship satisfaction & Male & 1.28 & 1.47 & $-1.539(.125)$ \\
\multirow{2}{*}{ Positive feelings for a friend } & Female & 1.51 & 1.35 & \\
& Male & 1.87 & 1.53 & $-1.826(.070)$ \\
Overall & Female & 2.16 & 1.28 & \\
& Male & 1.65 & 1.44 & $-1.881(.061)$ \\
\hline
\end{tabular}

Note. ${ }^{* \mathrm{p}<.05 ; * * \mathrm{p}<.005 ; * * * \mathrm{p}<.001}$

\section{Discussion}

The present study revealed that Vietnamese adolescents from ethnic minority groups got higher positive feeling and friendship satisfaction for the same-ethnicity best friend as well as for a cross-ethnicity best friend than those from the ethnic majority group. This finding is consistent with the ethnic differences in friendship quality reported in the literature although such differences were slightly significant (Rodebaugh et al., 2012; Rude \& Herda, 2010). As presented in the section above, in terms of same-ethnicity friendship quality, the differences in adolescents from both groups were not significant. However, in terms of cross-ethnicity friendship quality, a significant difference in the dimension "positive feelings for a friend" was found between ethnic minority and majority adolescents. The means of two dimensions and overall cross-ethnicity friendship quality for ethnic majority adolescents were slightly lower than those for ethnic minority adolescents. Because in Viet Nam, the chance to have friends from different ethnic groups is greater for ethnic majority adolescents than ethnic minority adolescents, ethnic minority adolescents tend to treasure the cross-ethnicity friendship more than ethnic majority adolescents.

It is surprising that ethnic minority adolescents got significantly higher for the dimension "positive feelings for a friend" in their cross-ethnicity friendship quality than those from the ethnic majority group. Compared to the finding from Quillian and Campbell (2003) study, they suggested that students from ethnic minority groups pursue maintaining a friendship network including several own-race friends. Furthermore, many previous studies found that cross-ethnicity friendships seem to be rated as not highly as the same-ethnicity friendships in terms of closeness (Rude \& Herda, 2010). According to them, cross-race friends are less likely to consider each other as 
friend. In reality, not all friendships are formed equally even "best" friendships. In the case of adolescents from ethnic minority groups in Viet Nam, they tend to have higher "positive feelings for a friend" within interracial friendships than those from the ethnic majority group. This is a positive sight for minor individuals as well as for complex ethnic society. However, future studies should attempt to deeply understand the mechanisms that promote strength and stability of that interethnic friendship, not simply its formation. These relationships may fail to persist over time or less sustainable. Consequently, the social benefits of cross-race ties and community social capital scholars are harder to obtain than they are commonly supposed to be (Briggs, 2007).

In terms of the differences in friendship quality between genders, the findings of this study are consistent with previous research (Bae, 2003; Mendelson \& Aboud, 1999, 2012; Rodebaugh et al., 2012; Thomas \& Daubman, 2001). Girls have higher friendship quality than boys for both the same-and cross-ethnicity friendship qualities. It is inferred that males and females perceive friendships in different ways. Females may be more attentive and sensitive to their friends. They tend to use more personality characteristics to describe their best friends. They also perceive their friendships to be closer, and emphasize the importance of trust and confidence in a friend more than males (Bae, 2003; Rodebaugh et al., 2012). Moreover, girls tend to be more supportive and focus on equality than boys. This is because they are generally two years ahead of boys in intellectual and social-cognitive functioning (De Goede et al., 2009). On the contrary, females are hypothesized to be more willing and tend to share more information on intimate topics with their best friends than their male counterparts. In addition, males may engage in less self-disclosure because of homosexual adjustment or societal gender role that stresses expressiveness for only females (Bae, 2003). Furthermore, boys in the same sex groups would be expected to present less expressive and engage in more agentic behaviors in order to secure and maintain mastery and power over the other partner, whereas girls would be expected to engage in more communal behaviors, such as striving for intimacy and connectedness (Zhou, Li, Zhang, \& Zeng, 2012). It is noticeable that in the present study, there were significant differences between genders in terms of the same-ethnicity friendship quality. Meanwhile, differences between genders in terms of cross-ethnicity friendship quality were not significant. The question of what factors contributed to these differences in gender in the same-ethnicity friendship quality of adolescents across ethnic groups in Viet Nam was therefore raised.

\section{Conclusions and Implications}

The findings from the present study draw a picture of the differences in the same-ethnicity and cross-ethnicity friendship quality of adolescents in Viet Nam. In terms of the cross-ethnicity friendship quality, adolescents from ethnic minority groups achieve significantly higher "positive feelings for a friend" than those from the ethnic majority group. Meanwhile, in terms of the same-ethnicity friendship quality, there was no significant difference in adolescents between ethnic majority and minority groups. In contrast, there was no any significant difference between genders in cross-ethnicity friendship quality; however, the differences between genders in the same-ethnicity friendship quality were significant. Girls got significantly higher "positive feelings for a friend" and overall same-ethnicity friendship quality than boys. These results are consisted with the findings from previous research on intra- and inter-ethnic friendship and gender comparison in friendship.

These results support the idea that future studies should pay more attention to exploring the quality of interethnic friendships of ethnic minority and majority adolescents in Viet Nam in order to suggest the ways how to promote interethnic friendships by encouraging equal-status contact in friendships, improving racial attitudes and reducing racial prejudice among society (Rude \& Herda, 2010). Future studies should be conducted on maintaining the stability of interethnic friendships of ethnic minority adolescents as well as encouraging adolescents from ethnic majority group form and improve their interethnic friendships. Cross-ethnicity friendships can serve as "bridging ties" that help connect disparate social networks and ensure a degree of cohesion in a society traditionally divided by ethnicity so that interethnic friendships can bring more chances for ethnic minority adolescents with resources and opportunities available to the majority group (Briggs, 2007). Because there were significant differences among genders in terms of the same-ethnicity friendship quality but not for the cross-ethnicity friendship quality, the question of what factors contributed to these differences highlights the need for future studies to focus on the same-ethnicity friendship quality by gender across ethnic groups in Viet Nam.

\section{Acknowledgements}

This study was supported by USM Fellowship to the first author from the Institute of Postgraduate Studies (IPS), Universiti Sains Malaysia (USM), Malaysia. We are indebted to all students and headmasters in Viet Nam who participated in the study. 


\section{References}

Bae, Y. A. (2003). Differences in friendship qualities of Korean and American college students. Honors Projects, Illinois Wesleyan University, USA.

Baron, R. A., Byrne, D., \& Branscombe, N. R. (2006). Social psychology. USA: Pearson Education, Inc.

Berndt, T. J. (2002). Friendship quality and social development. Current Directions in Psychological Science, 11, 7-10. http://dx.doi.org/10.1111/1467-8721.00157

Berndt, T. J., \& Keefe, K. (1995). Friends influence on adolescents adjustment to school. Child Development, 66, 1312-1329. http://dx.doi.org/10.2307/1131649

Blau, P. M. (1977). Inequality and Heterogeneity: A Primitive Theory of Social Structure. New York: Free Press.

Briggs, X. D. S. (2007). 'Some of my best friends are...': Interracial friendships, class, and segregation in America. City and Community, 6(4), 263-290. http://dx.doi.org/10.1111/j.1540-6040.2007.00228.x

Crandall, C. S., Schiffhauer, K. L., \& Harvey, R. (1997). Friendship pair similarity as a measure of group value. Group Dynamics: Theory, Research, and Practice, 1, 133-143. http://dx.doi.org/10.1037/1089-2699.1.2.133

De Goede, I. H. A., Branje, S. J. T., \& Meeus, W. H. J. (2009). Developmental changes and gender differences in adolescents' perceptions of friendships. Journal of Adolescence, 32, 1105-1123. http://dx.doi.org/10.1016/j.adolescence.2009.03.002

Friedman, M. (1989). Friendship and moral growth. The Journal of Value Inquiry, 23, 3-13. http://dx.doi.org/10.1007/BF00138682

Helm, B. W. (2005). Friendship. The Stanford Encyclopedia of Philosophy. Retrieved from http://plato.stanford.edu/entries/friendship

Larson, J. C. (2010). Attachment style and values in young adult friendships. In Bachelor Honors Thesis. Emory University, USA.

Mendelson, M. J., \& Aboud, F. (1999). Short report measuring friendship quality in late adolescents and young adults: McGill friendship questionnaires. Canadian Journal of Behavioural Science, 31(2), 130-132. http://dx.doi.org/10.1037/h0087080

Mendelson, M. J., \& Aboud, F. (2012). McGill Friendship Questionnaire-Respondent's affection (MFQ-RA). Measurement Instrument Database for the Social Science.

Moody, J. (2001). Race, school integration, and friendship segregation in America. American Journal of Sociology. http://dx.doi.org/10.1086/338954

Moore, S., \& Boldero, J. (1991). Psychosocial development and friendship functions in adolescence. Sex Roles, 25(9/10). http://dx.doi.org/10.1007/BF00290061

Nam, H. (2004). Vietnam image of the community of 54 ethnic groups: Introduction. Retrieved from $\mathrm{http} / / /$ web.cema.gov.vn/modules.php?name=Content\&mcid=1128

Nangle, D. W., Erdley, C. A., Newman, J. E., Mason, C. A., \& Capenter, E. M. (2003). Popularity, friendship quantity, and friendship quality: Interactive influences on children's loneliness and depression. Journal of Clinical Child and Adolescent Psychology, 32, 546-555. http://dx.doi.org/10.1207/S15374424JCCP3204_7

Parker, J. G., \& Asher, S. R. (1993). Friendship and friendship quality in middle childhood: Links with peer group acceptance and feelings of loneliness and social dissatisfaction. Developmental Psychology, 29(4), 611-621. http://dx.doi.org/10.1037/0012-1649.29.4.611

Quillian, L., \& Campbell, M. E. (2003). Beyond black and white: The present and future of multiracial friendship segregation. American Sociological Review, 68(4), 540-566. http://dx.doi.org/10.2307/1519738

Rodebaugh, T. L., Fernandez, K. C., \& Levinson, C. A. (2012). Testing the effects of social anxiety disorder on friendship quality across gender and ethnicity. Cognitive Behaviour Therapy, 41(2), 130-139. http://dx.doi.org/10.1080/16506073.2012.661451

Rude, J., \& Herda, D. (2010). Best friends forever? Race and the stability of adolescent friendships. Social Forces, 89(2), 585-608. http://dx.doi.org/10.1353/sof.2010.0059

Slavin, R. E., \& Cooper, R. (1999). Improving intergroup relations: Lessons learned from cooperative learning programs. Journal of Social Issues, 55(4), 647-663. http://dx.doi.org/10.1111/0022-4537.00140 
Telfer, E. (1971). Friendship. Proceedings of the Aristotelian Society, 71, 223-241.

Thomas, J. J., \& Daubman, K. A. (2001). The relationship between friendship quality and self-esteem in adolescent girls and boys. Sex Roles, 45(1/2), 53-65. http://dx.doi.org/10.1023/A:1013060317766

Waldrip, A. M., Malcolm, K. T., \& Jensen-Campbell, L. A. (2008). With a little help from your friends: The importance of high-quality friendships on early adolescent adjustment Social Development, 17(4), 832-852. http://dx.doi.org/10.1111/j.1467-9507.2008.00476.x

Williams, R. M. (1959). Friendship and social values in a suburban community: An exploratory study. The Pacific Sociological Review, 2, 3-10. http://dx.doi.org/10.2307/1388330

Zhou, H., Li, Y., Zhang, B., \& Zeng, M. (2012). The relationship between narcissism and friendship qualities in adolescents: Gender as a moderator. Sex Roles, 67, 452-462. http://dx.doi.org/10.1007/s11199-012-0169-8

\section{Copyrights}

Copyright for this article is retained by the author(s), with first publication rights granted to the journal.

This is an open-access article distributed under the terms and conditions of the Creative Commons Attribution license (http://creativecommons.org/licenses/by/3.0/). 